\title{
SOCIO-ECONOMIC FACTORS FOR THE JOB SATISFACTION OF THE PHYSICIANS IN BULGARIAN HOSPITALS
}

\author{
P. Atanasov ${ }^{1 *}$, B. Parashkevova ${ }^{1}$, J. Marinova ${ }^{1}$, G. Petrova ${ }^{1}$, S. Simeonov ${ }^{2}$, \\ I. Nencheva ${ }^{3}$, N. Penev ${ }^{3}$ \\ ${ }^{1}$ Medical Faculty, Trakia University, Stara Zagora, Bulgaria \\ ${ }^{2}$ National Health Insurance Fund, Stara Zagora, Bulgaria \\ ${ }^{3}$ Faculty of Economics, Trakia University, Stara Zagora, Bulgaria
}

\begin{abstract}
The physicians' job satisfaction and work motivation are the basic component of health service quality under the conditions of continuous public health reform. The purpose of this paper is to analyze the impact of some socio-economic factors on the professional satisfaction and motivation of the work of hospital physicians. Materials and methods. During the period from 2013 till 2015, was carried out a direct individual self-administered questionnaire containing 31 questions among 612 physicians, ${ }^{320}$ females and 292 males from 11 hospitals (5 district and 6 municipal) in South and South-Eastern Bulgaria. The data were processed by means of descriptive, correlation and graphic analysis using SPSS software, version 13.0. Results and discussion: Six socio-economic factors have been researched and analyzed: continuous improvement of the qualification; pay for labor; organization of work; administration of hospital activities; compliance with clinical pathways and work - personal life balance. Moderate ratings dominate for all these socio-economic factors, although their relative share varies significantly between $39 \%$ and $61 \%$. Significant differences were found between the doctors' assessments according to the type of hospital - municipal or district. The job satisfaction of the doctors in the municipal hospital prevails significantly in terms of the organization of the work and the management of the hospital, and their dissatisfaction with the payment is almost twice as strong. Conclusion: The results of the study focusing on the most valuable human capital aim at a better understanding of the functioning of hospital healthcare in Bulgaria and the prospects for its improvement.
\end{abstract}

Key words: job satisfaction, social-economics factors, self-administered questionnaire, hospital physicians

\section{INTRODUCTION}

The physicians' job satisfaction and work motivation are the basic component of health service quality under the conditions of continuous public health reform. The professional satisfaction of the physicians is a key issue of increasing global importance $(1,2$, $3,4)$. The healthcare development sets ever more serious requirements to them and they can respond appropriately to the increased expectations of the society if they are sufficiently qualified, motivated and satisfied with the work they have done $(5,6,7)$. The basic characteristics of the professional satisfaction and motivation to work of physicians in hospitals is necessary to be

\footnotetext{
*Correspondence to: P. Atanasov, Medical Faculty, Trakia University - Stara Zagora, E-mail address:dr.patanasov@gmail.com
}

known, as well as the role of different sociopsychological and socio-economic factors, influencing direct or indirect the satisfaction and motivation developed and maintained (8, $9,10)$.

The purpose of this study is to analyze the influence of some socio-economic factors on the professional satisfaction and motivation to work of the hospital physicians.

\section{MATERIALS AND METHODS}

In 2013 and 2015 a sociological survey was carried out among 612 physicians (292 men and 320 women of average age of $45.6 \pm 10.6$ years) working in five district and six municipal hospitals in South and SouthEastern Bulgaria. A direct individual selfadministered questionnaire containing 26 questions was used. The results were 
statistically processed with descriptive, variance (ANOVA) and correlation analysis (Pearson correlation coefficient). The SPSS software v. 13.0 was used.

\section{RESULTS AND DISCUSSION}

Six socio-economic factors have been examined and analyzed: qualification; ongoing raising the level of work pay; work organization in the hospital;
ATANASOV P., et al. activities;

$>\quad$ adherence to the clinical pathways and

balance between work in the hospital and private life.

The physicians working in the municipal hospitals are satisfied to a different extent with the care of the hospital management as regards their qualification (Figure 1).

Figure № 1. Degree of satisfaction $w$ ith the care of the hospital

management as regards the staff qualification

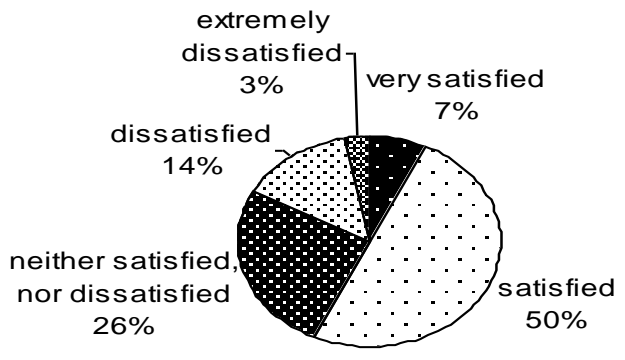

In relation to the actions undertaken in the clinic, respectively in the ward of the municipal hospital as regards the maintenance and further raising the level of qualifications of the physicians, the evaluation "good" (62 respondents) and the evaluation "very good" (39 respondents) prevails. It is worrying that a total number of 50 persons - medical staff having higher degree diploma evaluate these actions at their unit as "satisfactory" or "poor". Underestimating the need of medical work improvement may have adverse consequences for the work quality and the hospital as a whole.

Raising the level of qualification has a favorable influence on the satisfaction with the respondents work and the medical profession as well in district hospitals. This influence is statistically significant $(\mathrm{p}<0.001)$. Physicians who share that their hospital is working towards raising the level of qualification are more satisfied than those who are in the opposite opinion.
The clinical activity quality increase also changes the overall satisfaction with the profession and the job satisfaction $(\mathrm{p}<0.001)$ in these hospitals. Physicians whose practical work level is increased are more satisfied than those who consider that there is no such increase in the hospital where they work.

While the physicians' satisfaction is significantly predominates as regards the organization of work in the municipal hospital and hospital management, the dissatisfaction of these respondents with the work pay is almost twice stronger expressed than their satisfaction. Regarding the opportunities for medical staff having higher degree diploma in the municipal hospital to raise the level of qualification, the positive answers slightly prevail over the negative answers. As a whole, the relative shares of the positive answers to the questions for physicians' satisfaction with the mentioned working conditions in the municipal hospitals, according to "sex" and "total", are compared against the negative answers in Tables 1-3.

\begin{tabular}{|l|l|l|ll|}
\hline \multicolumn{5}{|c|}{ Table 1. A comparison of results how many male physicians are satisfied with different } \\
working conditions in the municipal hospitals \\
\hline Work & Hospital & Work pay & Professional & skills \\
organization & management & Yes $-38 \%$ & development & \\
Yes $-80 \%$ & Yes $-82 \%$ & No- $62 \%$ & Yes $-53 \%$ & \\
No-20\% & No-18\% & & No-47\% & \\
\hline
\end{tabular}


ATANASOV P., et al.

\begin{tabular}{|l|l|l|lr|}
\hline \multicolumn{5}{|c|}{ Table 2. A comparison of results how many female physicians are satisfied with different } \\
working conditions in the municipal hospitals \\
\hline Work & Hospital & Work pay - & Professional & skills \\
organization & management - Yes - & Yes - 36\% & development & \\
Yes $-78 \%$ & $84 \%$ & No- $64 \%$ & Yes $-55 \%$ \\
No-22\% & No-16\% & & No-45\% & \\
\hline
\end{tabular}

\begin{tabular}{|l|l|l|ll|}
\hline \multicolumn{5}{|c|}{ Table 3. A comparison of results how many respondents are satisfied with different } \\
working conditions in the municipal hospitals \\
\hline Work & Hospital & Work pay & Professional & skills \\
organization & management & Yes $-36 \%$ & development & \\
Yes $-79 \%$ & Yes $-84 \%$ & No- $64 \%$ & Yes $-55 \%$ & \\
No-21\% & No-16\% & & No-45\% & \\
\hline
\end{tabular}

We have analyzed the medical staff public activity, in particular as regards their attitude towards expressing their opinion to the manager: "I express my opinion when it is required by the manager"- 63\%; "I deliver my opinion whether required or not" - 32\%; "My opinion is never required" - $5 \%$.

The majority of respondents participate (in smaller or in greater extent) actively in decision making for the clinic activity and development, respectively the ward in the municipal hospital where they work. This is an evidence of their active citizenship.

The level of respondents' satisfaction with the existing coordination between the clinics, wards, diagnostic and other units of the municipal hospital is compared. According to 101 respondents, the coordination in their hospital is good (63\%), according to 33 - very good (20\%), and according to 27 - insufficient $(17 \%)$.

The degree of influence of six socio-economic factors on the physicians' job satisfaction in the municipal hospitals is estimated through a 5-degree scale - from "very strong" to "none". The influence of the ongoing raising the level of qualification on the physicians' job satisfaction in the municipal hospitals is demonstrated in Figure 2; the influence of the work pay - in Figure 3; the influence of the hospital work organization - in Figure 4; the influence of the administration of the hospital activities - in Figure 5; the influence of the adherence to clinical pathways - in Figure 6 and the influence of the balance between work in the hospital and private life - in Figure 7. Moderate ratings dominate as regards all factors, although their relative share varies considerably - between $39 \%$ and $61 \%$.

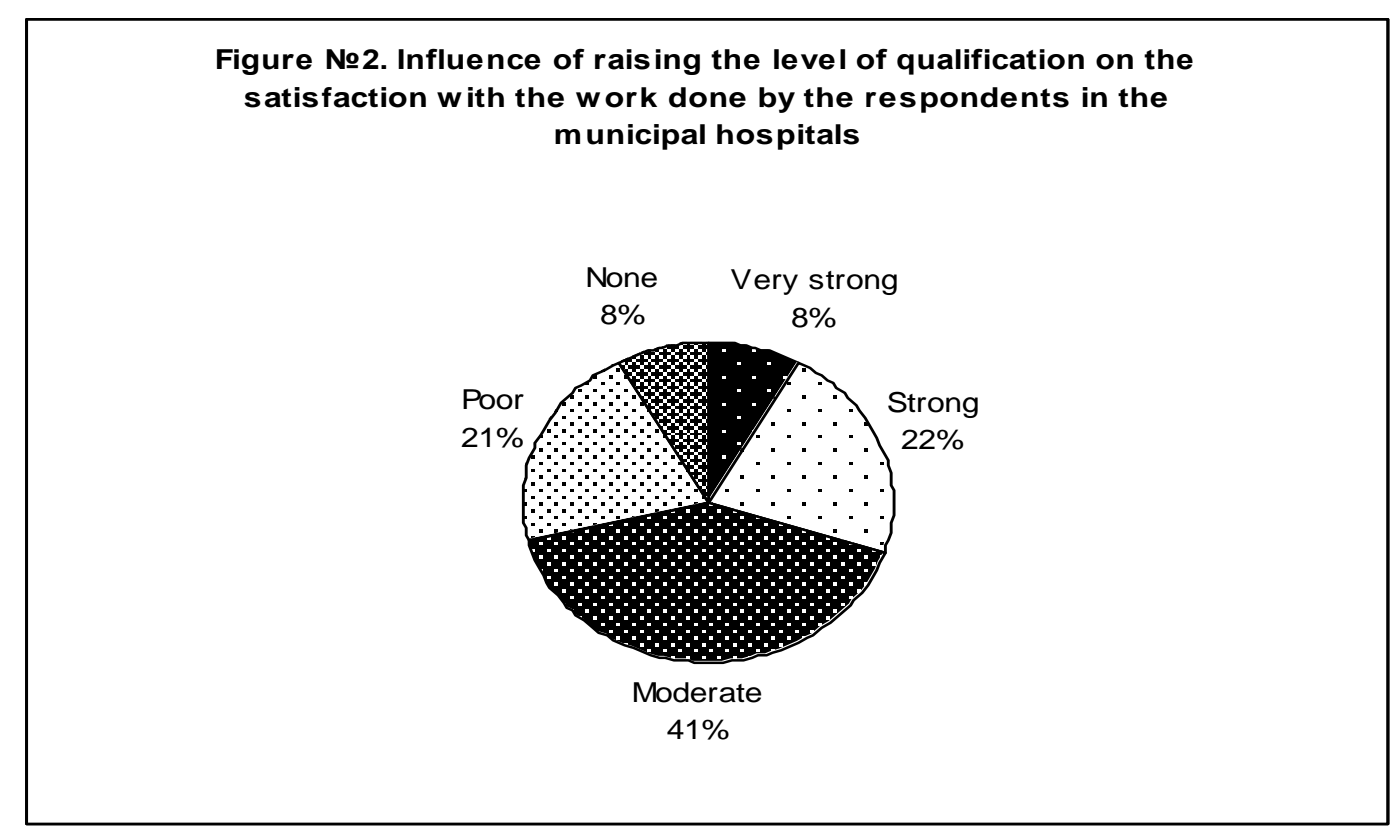


Figure № 3. Influence of the work pay on the satisfaction with the work done by the respondents in the municipal hospitals

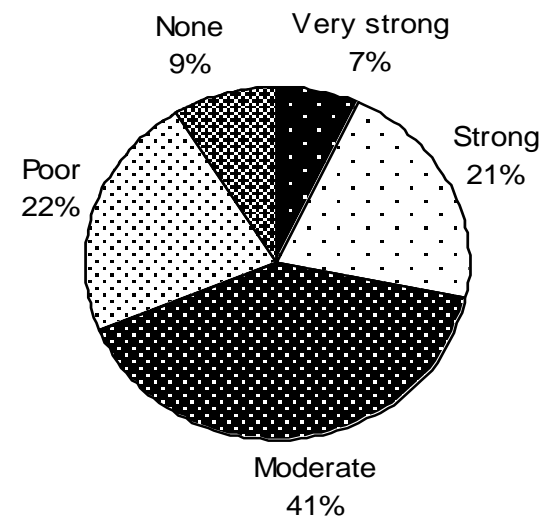

Figure №4. Influe nce of the work organization on the satisfaction with the work done by the respondents in the municipal hospitals

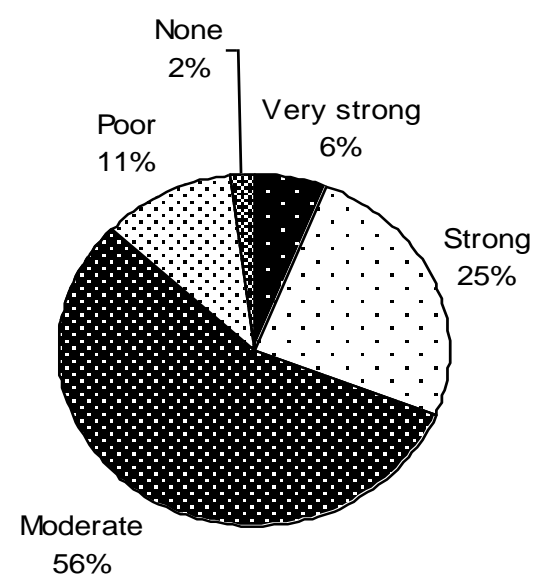

Figure №5. Influence of the administration of the activities in the municipal hospital on the satisfaction with the work done by the respondents

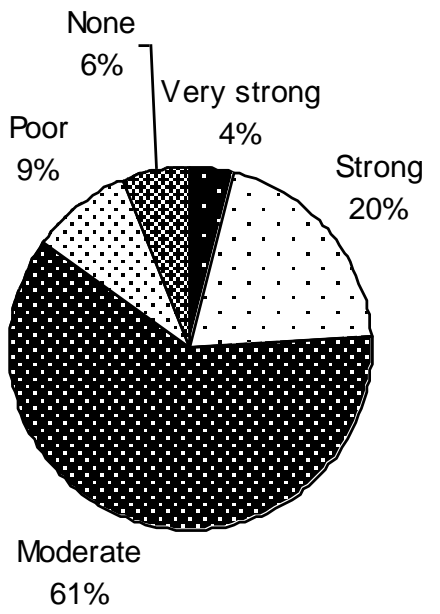


Figure № 6. Influence of the adherence to the clinical pathways on the satisfaction with the work done by the respondents in the municipal hospitals

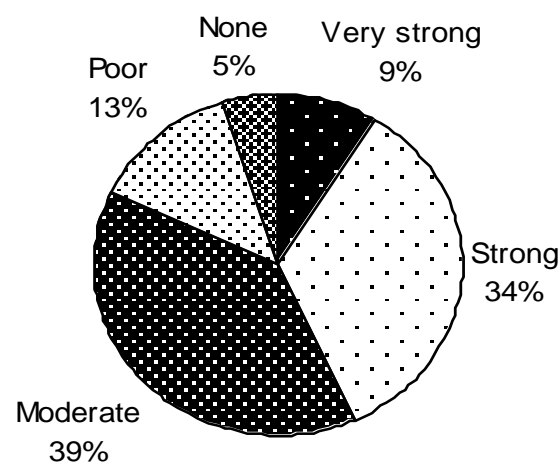

Figure № 7. Influence of the balance between work in the municipal hospital and private life on the satisfaction with the work done by the respondents

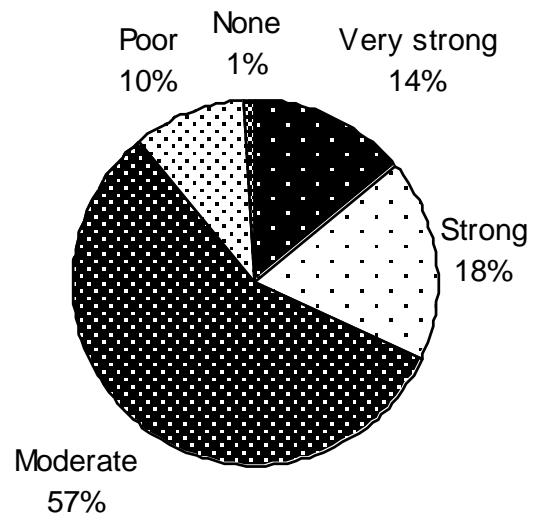

It is worth mentioning the prevalence of moderate ratings in relation to all the factors mentioned, although it is expressed in a different extent. The factors occupying leading place in the group with such ratings are "administration of the activities" (98 responses) (Figure 5), "balance between work and private life" (92 answers) (Figure 7) and "work organization" (90 responses) (Figure 4).

The significant absolute number and the high relative share of the total ratings of the influence are impressive - "strong" and "very strong" of "adherence to the clinical pathways" factor (a total of 70 responses) (Figure 6).

Respondents were asked to note the three most significant streams for changes in the hospital system in case they occupy appropriate leading position in the hospital hierarchy. Leading place among the nine proposals is occupied by "it is urgent to be appointed specialists in the wards" (110 responses or 22.77\%), "development of a program and performance of specific actions for physicians' development" (78 responses or $16.15 \%$ ), "renewal of the equipment and tools" (75 responses or $15.53 \%$ ) and "better control over the staff activity" (74 responses or $15.32 \%$ of the cases). Last place is occupied by priorities as regards "improvement of the relations in the team" (14 responses or $2.90 \%$ ) and "provision of better information to patients" (10 responses or $2.07 \%$ of the cases). 
The individual rating of the overall condition of the clinic, respectively the ward of the municipal hospital becomes visible through the analysis of the answers to the indirect question about the possible recommendation of this hospital to relatives of the respondents. The strong positive rating expressed by response "yes, in all cases" is available more frequent than 3.57 times compared to essentially negative rating expressed by response "I would recommend as an exception" (125 vs. 35 responses). Only one respondent $(0.62 \%$ of the cases) would not recommend to his/her relatives the hospital where he/she works.

The semantic analysis of the answers to the open questions in the questionnaire on the influence of some socio-economic factors on the professional satisfaction and motivation of doctors in hospitals are established a number of categorical assessments of the functioning of hospital healthcare in Bulgaria in recent years. There are also specific suggestions and recommendations. We would just mention some of the most typical answers to the open question: "What would you say in addition about the issues being discussed ?":

"I would like to change the model of health insurance by introducing personal insurance bills, facilitating access to wider coverage of true prophylaxis - diet, motor regimen, tobacco damage, alcohol, computer broadcasting, etc."

"Introduce a new way to compensate hospitals and eliminate clinical pathways as they drain money".

"The level of Bulgarian doctors does not give way to the Western colleagues, but the system of payment is vicious. We are not the servants of the patients, but the skilled people with dignity! ".

"Determine the value of the activities (medical procedures)".

"Limit the costs of the hospital to physicians who are physically inactive in the hospital, and the relieved means to be transferred to the workers there".

"You need to reduce or find an alternative to stacks of documentation".

"Improvement of working conditions, introduction of modern equipment for diagnostics and treatment and new methods"

"Pay attention to the safety of service personnel while working with aggressive patients and their relatives".
ATANASOV P., et al.

"There is a possibility to apply the new methods of treatment without "Emergency measures are needed for the retention of young doctors in Bulgaria".

"There must be motivation of young physicians, control of quality work and competent hospital management".

"Better financing, modern equipment, timearriving reagents, repairs of the cabinets creating human conditions for work!".

"Improving the toolbox, visiting international congresses and meetings, improving the organization of work in the hospital".

"Creating opportunities and financial provision and continuing education and research work".

"Introduction of Clinical Trials".

"Appropriate financial treatment (evaluation) of the work of medical specialists is needed".

"Minimize the writing of doctors".

"I do not think that turning ourselves into scribes, administrators, accountants, and socalled scribes helps our direct work as doctors constantly demonstrating that they are doing their job."

"Raise the qualifications of doctors and nurses, as the hospital management invests in their training."

"Hospital to provide free qualification courses for doctors".

"The access of the average patient (especially from the province) needs to be improved".

\section{"Improving Patient Conditions in the Hospital".}

It should be emphasized that even the respondents who are satisfied with their professional realization at the hospital - or at all, or only on certain aspects of this complex problem, express open disagreement with some legal unrest and unlawful organizational practices both in the modern hospital healthcare in general and in their hospital and offer a number of rational ideas for the further improvement of the medical care of the patients.

\section{CONCLUSION}

The main socio-economic conditions influencing the satisfaction are the working conditions and payment, work organization and the opportunities for raising the level of qualification. 
The results represent differences in the attitude of the physicians working in municipal and regional hospitals and raise the question of the real socio-economic status of these medical establishments in Bulgaria.

The study focuses on the most valuable capital - the human and directs to a better understanding of the hospital healthcare functioning and gives a certain perspective for its improvement.

\section{REFERENCES}

1. Balch CM, Shanafelt TD, Sloan J, Satele DV, Kuerer HM. Burnout and career satisfaction among surgical oncologists compared with other surgical specialties. Ann Surg Oncol., 18, No 1, 16-25. 2011.

2. Bendixen HJ, Ellegård K. Occupational therapists' job satisfaction in a changing hospital organization - a time-geographybased study. Work., 47, No 2, 159-171, 2014.

3. Parashkevova B., J.Marinova, Job satisfaction of general practitioners results from an empirical study, Forth international congress" From science to people", NSOPLB, Povdiv, ISBN 978-6197208-02-3: 92-100, 2014.

4. Gruneberg MM. Understanding job satisfaction. New York, John Wiley and Sons, p.170, 1979.

5. Alekova S., Stoynov V., Slavova V., B. Parashkevova, Platikanova M., Study of the
ATANASOV P., et al. effect of some stressful factors in the work of general practitioners and specialists of otorhinolaryngology, Trakia Journal of Sciences, Vol. 9, Suppl. 1: 21-25, 2011

6. Parashkevova B., J.Marinova, General Practitioners' Career Characteristics and Factors: Results from an Empirical Study, General Medicine, vol.XVIII, 2: 28-33, 2016

7. M. Ivanova, E. Karaslavova, S. Tufkova Competition And Collaboration In Market Condition Through The General Practitions' View, General medicine, Iss.1: 3-8, 2008.

8. M. Tarnovska,R. Karadjova, R. Dimova, Dimensions of Work Ethics in the Professional activity of Physicians, Public Health and Health care in Greece and Bulgaria: the Challenge of cross-border Collaboration: Papazissis Publishers Athens,: 1259-1264, 2010

9. Gilles,I., B.Burnand, I.PeytremannBridevaux. Factors associated with healthcare professionals' intent to stay in hospital: a comparison across five occupational categories,Int. J. Qual. Health Care, 26(2),158-166, 2014.

10.Slavova V.B., Dimitrova D.A., Ivanov V.A., Parashkevova B.M., Vasileva A.V., Platikanova M.S., State policy for training the population for protective actions during disastrous situations, International Research Journal № 4 (46): 122-124, 2016 